\title{
Synthesis and Evaluation of Antimicrobial Activity of 1, 3, 4-Thiadiazole Analogues for Potential Scaffold
}

\author{
Sagar Sahu ${ }^{1}$, Tanesh Sahu ${ }^{2}$, Gunjan Kalyani ${ }^{1}$, Bina Gidwani ${ }^{1}$ * \\ ${ }^{1}$ Columbia Institute of Pharmacy, Raipur, India \\ ${ }^{2}$ Shri Rawatpura Sarkar Institute of Pharmacy, Kumhari, India
}

Received June 4, 2020

Reviewed October 22, 2020

Accepted March 4, 2021

*Corresponding Author

Bina Gidwani

Columbia Institute of Pharmacy, Raipur, India

Tel: +91-99-8190-3827

E-mail: beenagidwani@gmail.com
Objectives: Pathogenic microbes are causal agents for various types of severe and even lethal infectious diseases. Despite of development in medication, bacterial and fungal infections still persist to be a vital problem in health care. Bacteria and several fungal species have shown resistance to antibiotics used in treatment to current medications. Therefore, it is a considerable field of interest in the design and development of novel compounds with antimicrobial activity.

Methods: The compounds bearing a heterocyclic ring play an imperative role among other organic compounds with pharmacological activity used as drugs in human for control and cure of various infections. Thiadiazoles containing nitrogen-sulfur atom as part of their cyclic structure which shown wide-ranging application as structural units of biologically active molecules and are very useful intermediates in Medicinal Chemistry.

Results: The effectiveness of the thiadiazole nucleus was established by the drugs currently used for the treatment of various infections. 1,3,4-Thiadiazoles and some of their derivatives are widely studied because of their broad spectrum of pharmacological activities.

Conclusion: In the present work, a series of 1,3,4-Thiadiazole derivatives were synthesized by cyclization of a group of various benzaldehyde with thiosemicarbazide in the presence of various reagent like $\mathrm{FeCl}_{3}, \mathrm{HCHO}$ by losing a molecule of water. These derivatives were found to possess prominent antimicrobial activity.

Keywords: 1,3,4-thiadiazole, heterocyclic, thiosemicarbazide, cyclization, antimicrobial

\section{INTRODUCTION}

Thiadiazoles are classified under azole compounds. These are five-membered heterocyclic compound containing a sulfur atom with two nitrogen atoms. Presence of two double bonds gave aromatic ring; with the name Thiadiazole originating from the Hantzsch - Widman nomenclature. The thiadiazole was firstly described by Fischer in 1882, but the nature of the ring system was demonstrated by Freud and Kuhn in 1890. Thiadiazole and their structurally related chemical compounds are called 1, 3, 4-thiadiazole (two nitrogen and one sulphur heteroatom in a five- membered cyclic ring). The structure is shown in Fig. 1. Basically, there are four isomeric forms of thiadiazole i.e,

\section{* 1, 2, 3-thiadiazole \\ * 1, 2, 5-thiadiazole \\ * 1, 2, 4-thiadiazole \\ * 1, 3, 4-thiadiazole}

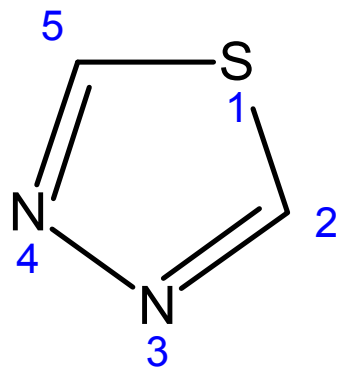

Figure 1. Structure of 1,3,4-thiadiazole molecule. 
1, 3, 4-thiadiazole is amongst the highly useful isomeric form because of its diverse biological actions in body. In particular, compounds bearing the 1, 3, 4-thiadiazole nucleus is known to have exclusive action against bacterial infection and anti-inflammatory activities in body. Structurally substituted derivatives of Thiadiazole have also been found to bear diverse therapeutic activities such as analgesic, antimicrobial, antitubercular, anticonvulsant and anti-hepatitis B viral activities [13]. The properties are listed in Table 1 . The biological activity of Thiadiazoles is because of strong aromaticity of the ring system that offers higher in vivo stability. Thiadiazoles is a bioisosteric replacement of Thiazole moiety. Also, it is a bioisostere of Oxadiazole, Oxazole and Benzene. Substitution of these heterocyclic systems with a Thiadiazole by and large leads to analogues with improved activity because sulfur atom imparts enhanced liposolubility.

An antimicrobial is an agent that either kills or inhibits the growth of microbes. Thus, this microbial agent may be either a chemical compound or any physical agents. These agents efficiently interfere with the growth and reproduction of causative microorganisms like bacteria, fungi, parasites, virus etc. The breakthrough obtained with the discovery of Penicillin in 1940 lead to development of an era which formed the basis of the prospering modern antimicrobial therapy. Diverse antibiotics and other agents have been discovered after the penicillin. The breakthrough of the antibiotic penicillin in the early 1940s became the vital mainstay for the era of. The most important discovery subsequently after the introduction of Penicillins in to be the pronouncement of the basic skeleton of which they were made. Thus, it was revealed that it could be modified chemically in order to improve their characteristics. To summarize, it can be said that antimicrobial agents are used to manage accessible illness and they can be used as prophylaxis for definite medical conditions and other surgical procedures $[4,5]$. Based

Table 1. Properties of 1,3,4-thiadiazole

\begin{tabular}{ll}
\hline \multicolumn{1}{c}{ Properties of 1,3,4-thiadiazole } \\
\hline Name & $1,3,4$-thiadiazole \\
\hline Molecular formula & $\mathrm{C}_{2} \mathrm{H}_{2} \mathrm{~N}_{2} \mathrm{~S}$ \\
\hline Molecular weight & $86.112 \mathrm{~g} / \mathrm{mol}$ \\
Melting Point & $42^{\circ} \mathrm{C}$ \\
Boiling Point & $127.6 \pm 23.0^{\circ} \mathrm{C}$ at $760 \mathrm{~mm} \mathrm{Hg}$ \\
Solubility & Soluble in alcohol and ether and slightly \\
& soluble in water \\
\hline
\end{tabular}

on these facts the purpose of present research work was to synthesize some thidiazole derivatives that have broad spectrum of antimicrobial activity and to project these synthesized derivatives as an alternative to antibiotics on the basis of their action.

\section{MATERIALS AND METHODS}

All the chemicals and reagents used in the study were purchased from Sudarshan Chemicals, Raipur and were of commercial grade. Melting points were determined by melting point apparatus and were left uncorrected. The chemical used were Aromatic aldehyde, Thiosemicarbazide, Pthalmide, $p$ nitro aniline, Ethanol and Sulphuric acid.

\section{Scheme for synthesis}

The literature survey revealed that Thiadiazole moiety is an imperative heterocyclic system with different and diverse biological activities. Therefore, the objective was to prepare different Thiadiazole derivatives and evaluate them for their antimicrobial, analgesic, antioxidant, anti-inflammatory and antihelmintic. The synthesis of 1,3,4-Thiadiazole derivatives is attracting attention of researchers because it has multitudinous biological activities as discussed earlier. Therefore, synthesis of different derivatives of 1,3,4-Thiadiazole has been done and was evaluated for anti-microbial activity.

\section{1) Step I}

In a $500 \mathrm{ml}$ beaker filled with warm alcohol (150 ml), pDimethylbenzaldehyde $(0.1 \mathrm{~mol})$ was added. The solution of Thiosemicarbazide $(9.1 \mathrm{~g}, 0.1 \mathrm{~mol})$ in hot water $(150 \mathrm{ml})$ was prepared and added into the beaker, with slow mixing and continuous stirring. The precipitated product was (Compound I) was filtered off and recrystallized from 50\% ethanol [6].

\section{2) Step II}

Compound I (0.025 g) was suspended in $150 \mathrm{ml}$ of distilled water in $500 \mathrm{ml}$ beaker. Ferric chloride solution was added to the beaker (12.165 g. $0.075 \mathrm{~mol}$ in $150 \mathrm{ml}$ distilled water). The reaction mixture was heated and maintained at temperature of $80-90^{\circ} \mathrm{C}$ for $1-2$ hours. Then reaction mixture was filtered hot. A mixture of citric acid $(11.55 \mathrm{~g}, 0.055 \mathrm{~mol})$ and sodium citrate ( $7.35 \mathrm{~g}, 0.025 \mathrm{~mol}$ ) was added to the filtrate and stirred well. After cooling the solution to room temperature, it was recrystalized with $50 \%$ aqueous ammonia. The precipitate (Compound 
II) separated out was filtered and recrystalized from $25 \%$ aqueous ethanol. Then, compound II was identified using TLC, with mobile phase of Benzene, Ethyl acetate, Ethanol in ratio of (4:2:1) using silica gel $G$ as stationary phase. The detection was done by using iodine vapours.

\section{3) Step III}

A methanolic solution of compound II ( $2 \mathrm{~g}, 0.001 \mathrm{~mol})$ was placed into a three-neck flask equipped with a stirred and dropping funnel. The solution was stirred to dissolve the compound completely. To this, methanolic solution, formaldehyde ( $7 \mathrm{ml}, 37 \%)$ was added drop wise for 15-20 minutes. The resulting mixture was stirred for around $30 \mathrm{~min}$. to complete reaction with formaldehyde for yielding of methyl derivatives. The methanolic solution of Phthalimido (1.5 g, $0.001 \mathrm{~mol}$ ) was added drop wise with continuous stirring for about half an hour at the temperature of $30^{\circ} \mathrm{C}$. The solution was refluxed for two hours at $65-70^{\circ} \mathrm{C}$. It was then allowed to cool in ice water. The solid obtained (Compound III) was filtered and washed thoroughly with hot water then air dried [7-9]. The steps for the synthesis are highlighted from Fig. 2 to 5.

\section{Characterization of synthesized compounds}

\section{1) Thin layer chromatography}

Thin layer chromatographic studies have been performed for the synthesized compounds (I), (II), (III) and (IV). The solvent system for the entire synthesized compound was same. The procedure for Rf value determination through TLC is discussed below -

- Sillica gel G used for TLC was activated in hot air oven at $100^{\circ} \mathrm{C}$ for 1 hour.

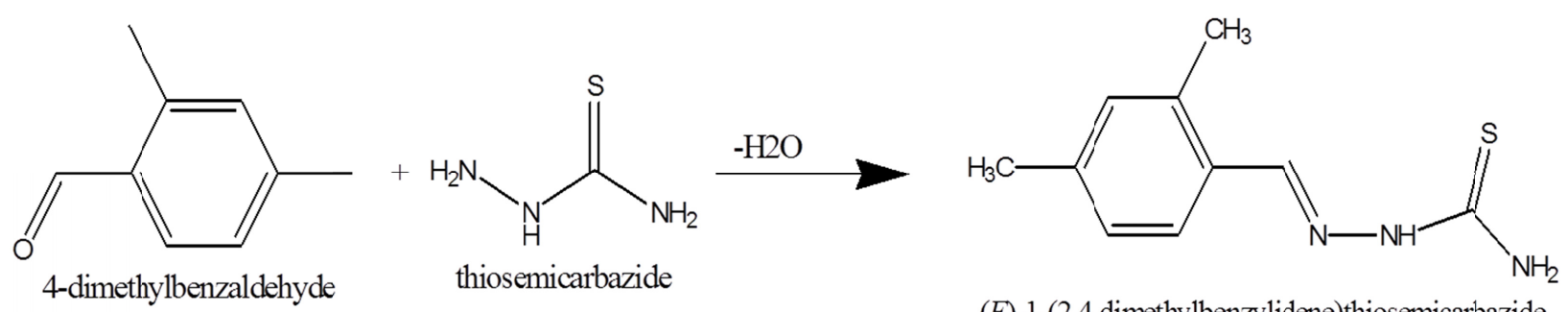

(E)-1-(2,4-dimethylbenzylidene)thiosemicarbazide

Figure 2. Preparation of (E)-1-(2,4-dimethylbenzylidene) thiosemicarbazide (Compound I).

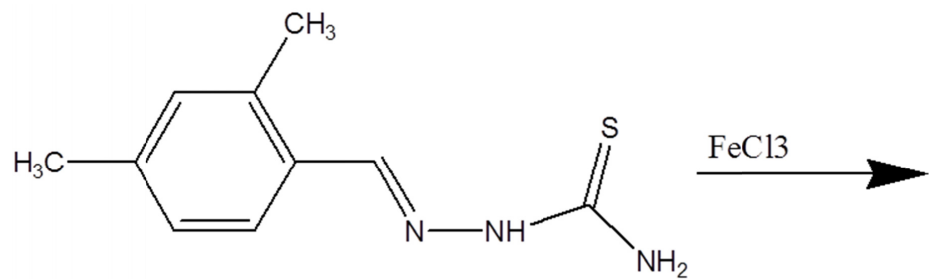

(E)-1-(2,4-dimethylbenzylidene)thiosemicarbazide

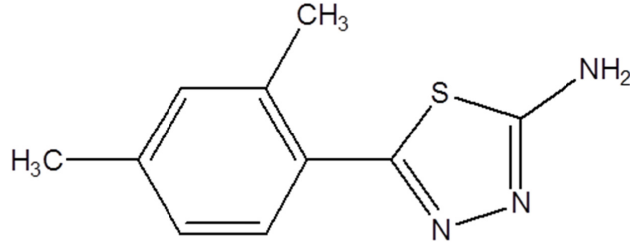

5-(2,4-dimethylphenyl)-1,3,4-thiadiazol-2-amine

Figure 3. Preparation of 5-(2,4-dimethylphenyl)-1,3,4-thiadiazol-2-amine (Compound II).
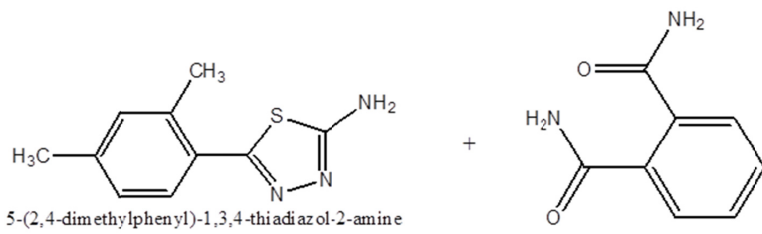

phthalamide

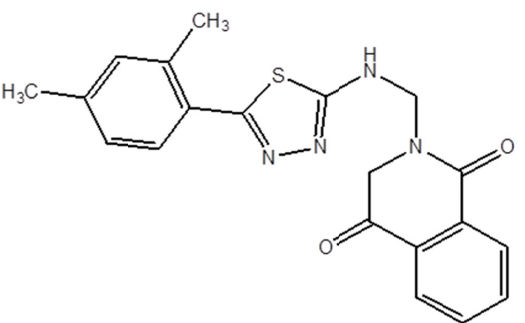

2-((5-(2,4-dimethylpheny1)-1,3,4-thiadiaz ol-2-ylamino)methyl)-2,3-dihy droi soquin oline-1,4-dione

Figure 4. Preparation of 2-((5-(2,4-dimethylphenyl)-1,3,4-thiadiazole-2-ylamino)methyl)-2,3-dihydroisoquinoline-1,4-dione (Compound III). 


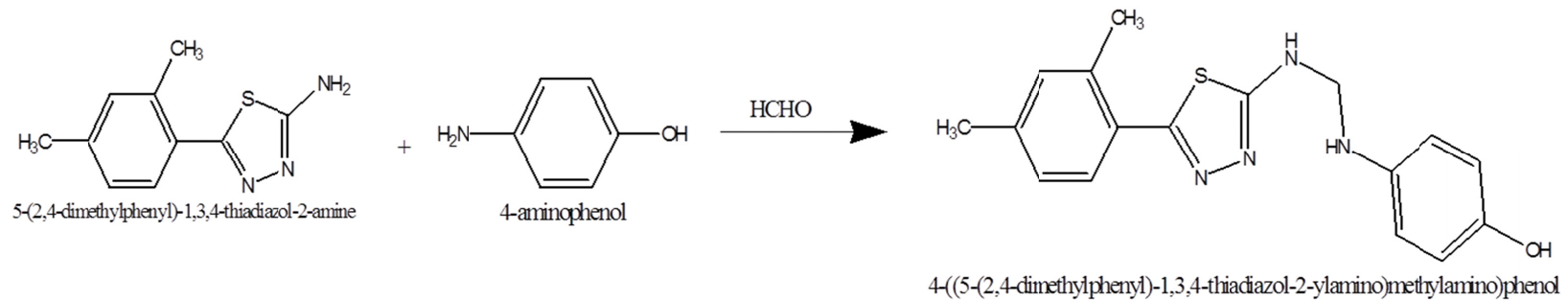

Figure 5. Preparation of 4-((5-(2,4-dimethylphenyl)-1,3,4-thiadiazol-2-yalmino)methylamino)phenol (Compound IV).

- TLC plate at a distance $2 \mathrm{~cm}$ from the base, marks were made on the line for sample application.

- The sample was spotted on the line with the help of capillary tube and it was allowed to dry.

- The plate was placed in the developing chamber with mobile phase.

- Mobile phase was selected by hit and trial method.

- Various ratios of solvent systems were prepared and the spots was visualized and $\mathrm{Rf}$ value was calculated.

- After visualization of spots solvent system or mobile phase was selected.

TLC plates were run using solvent system benzene: ethyl acetate: ethanol in the ratio of 4:2:1 for synthesized compounds. The spots detection was done by using iodine vapor and $\mathrm{Rf}$ value was calculated [10].

\section{2) Melting point determination}

- A small amount of drug was filled into capillary tube upto $1 / 3$ volume then other opening mouth was sealed by heating. Now this capillary tube was attached to thermometer.

- The thermometer with capillary tube was dipped into thiel's tube containing liquid paraffin.

- Thiel's tube was heated by the help of burner.

-When the compound starts melting, then exact temperature was noted [11].

\section{3) Elements detection}

(1) Test for nitrogen

(1) A small piece of $\mathrm{Na}$ metal was heated in a fusion tube with the organic compound.

(2) The formed ionic salts were extracted from the fused mass by boiling it with distilled water. This is called sodium fusion extract.

(3) The extract was boiled with $\mathrm{FeSO}_{4}$ and acidified with concentrated $\mathrm{H}_{2} \mathrm{SO}_{4}$.
(2) Test for sulphur

(1) A small piece of $\mathrm{Na}$ metal was heated in a fusion tube with the organic compound.

(2) The formed ionic salts were extracted from the fused mass by boiling it with distilled water. This is called sodium fusion extract.

(3) The extract was treated with sodium nitroprusside.

(3) Test for oxygen

(1) Ceric ammonium test (Alcohol oxygen)

i) $1 \mathrm{ml}$ solution of organic compound was taken into test tube.

ii) Then few drops of ceric ammonium nitrate solution were added to solution.

iii) The mixture was allowed to stand for 15 minutes.

(2) 2,4-dinitrophenyl hydrazine test (carbonyl oxygen)

i) Five drops of the compound to be tested was mixed with 5 drops of the dinitrophenylhydrazine reagent in $2 \mathrm{ml}$ of ethanol.

ii) Then tube was shaken.

iii) The mixture was allowed to stand for 15 minutes [12].

\section{Estimation of antimicrobial activity}

The antibacterial activity of synthesized derivative of 1,3 , 4-Thiadiazole derivatives were carried out on Bacillus subtilis and Escherichia coli by using Agar diffusion method. Ciprofloxacin was used as a standard drug for evaluation. Initially, the stock cultures of bacteria were revived by inoculating in broth media and grown at $37^{\circ} \mathrm{C}$ for $18 \mathrm{hrs}$. The agar plates of the above media were prepared, and wells were made in the plate. Each plate was inoculated with $18 \mathrm{hr}$ old cultures $\left(100 \mu \mathrm{l}, 10^{-4}\right.$ cfu) and spread evenly on the plate. After $20 \mathrm{~min}$, the wells were filled with of compound and antibiotic at different concentrations. All the plates were incubated at $37^{\circ} \mathrm{C}$ for $24 \mathrm{hrs}$ and the diameter of inhibition zone ( $\mathrm{mm}$ ) were noted [13]. 


\section{RESULTS}

Total 4 compounds were synthesized. These compounds were characterized for physicochemical Properties like molecular formula, molecular weight, melting point and yield. TLC was done and $\mathrm{Rf}$ value of synthesized compounds were estimated. Results are shown in Table 2. The diagrammatic representation of TLC plates is listed in Fig. 6.

\section{Element detection}

The synthesized compounds were estimated for the presence of elements like nitrogen, sulpher and oxygen etc. Results are shown in Table 3.

\section{Spectral characterization of compounds by FTIR}

FTIR spectrum of the derivatives were recorded by $\mathrm{KBr}$ Press Pellet method (Shimadzu FTIR 8400S, Japan). The characteristic peaks along with their functional group are shown in Fig. 7.

\section{Antimicrobial activity of synthesized compound}

The results indicated that among all the three tested compounds, III and IV showed good activity against all the fungal

Table 2. Physicochemical properties of synthesized compounds

\begin{tabular}{ccccccc}
\hline S. No. & Compound & Molecular formula & Molecular weight (g/mole) & \% Yield & Melting point & Rf value \\
\hline 1 & $\mathrm{I}$ & $\mathrm{C}_{10} \mathrm{H}_{14} \mathrm{~N}_{4} \mathrm{~S}$ & 222.309 & 74 & $104^{\circ} \mathrm{C}$ & 0.8 \\
2 & II & $\mathrm{C}_{10} \mathrm{H}_{12} \mathrm{~N}_{4} \mathrm{~S}$ & 220.29 & 68 & $108^{\circ} \mathrm{C}$ & 0.79 \\
3 & III & $\mathrm{C}_{18} \mathrm{H}_{15} \mathrm{~N}_{5} \mathrm{O}_{2} \mathrm{~S}$ & 365.40 & 61 & $106^{\circ} \mathrm{C}$ & 0.6 \\
4 & IV & $\mathrm{C}_{16} \mathrm{H}_{17} \mathrm{~N}_{5} \mathrm{OS}$ & 327.40 & 57 & $108^{\circ} \mathrm{C}$ & 0.6 \\
\hline
\end{tabular}

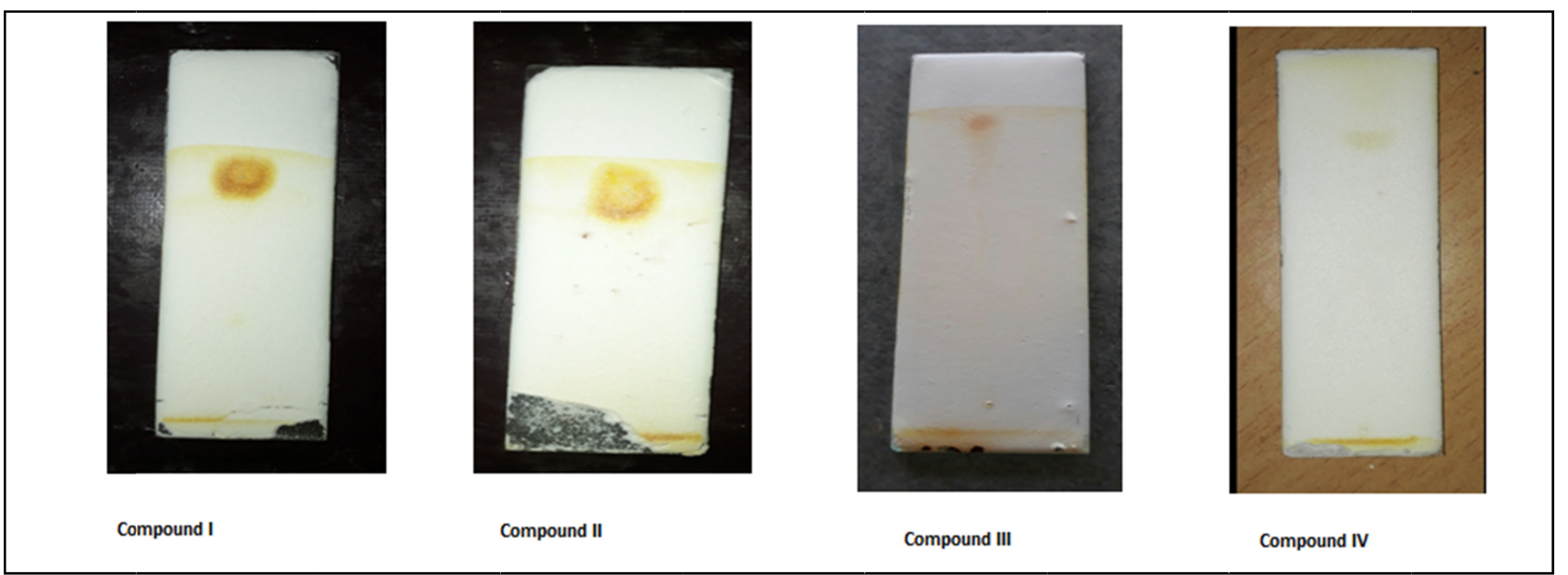

Figure 6. TLC of synthesized compounds.

Table 3. Element detection of synthesized compound

\begin{tabular}{|c|c|c|c|c|c|c|}
\hline S. No. & Test & Observation & Compound I & Compound II & Compound III & Compound III \\
\hline 1 & Test for $\mathrm{N}_{2}$ & Prussian blue precipitate & Present & Present & Present & Present \\
\hline 2 & Test for $\mathrm{S}$ & Black precipitate & Present & Present & Present & Present \\
\hline 3 & & & Test for $\mathrm{O}_{2}$ & & & \\
\hline$A$ & $\begin{array}{l}\text { Ceric ammonium test } \\
\text { (Alcohol oxygen) }\end{array}$ & Pink colour & Absent & Absent & Absent & Present \\
\hline$B$ & $\begin{array}{l}\text { 2,4-dinitrophenyl hydrazine } \\
\text { test (Carbonyl oxygen) }\end{array}$ & Crystalline precipitate & Absent & Absent & Present & Absent \\
\hline
\end{tabular}




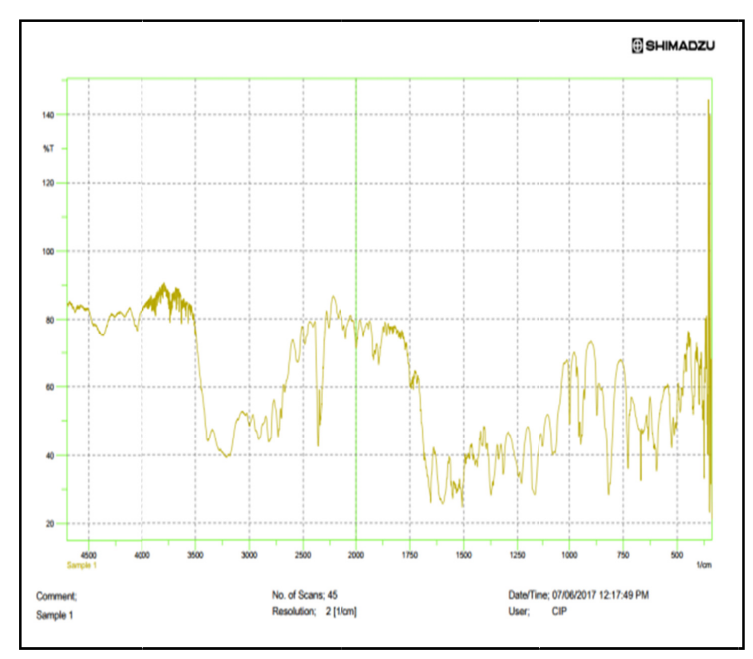

Compound I

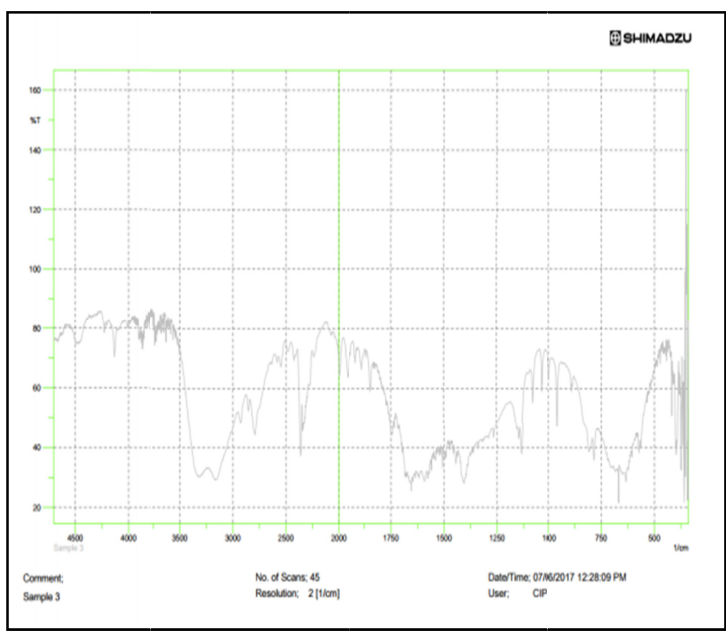

Compound III

Figure 7. FTIR spectra of synthesized compounds.

strains at concentrations of 1 and $0.5 \mathrm{mg} / \mathrm{mL}$ compared to standard drug. None of the synthesized compounds were superior to the standard drug against various tested microbial strains; However, the antifungal activities of some of the compounds are comparable to those of standard. Results of antimicrobial activity are shown in Table 4 and Fig. 8, 9.

\section{DISCUSSION}

In the present research work antibacterial activity of synthesized derivatives was performed by Agar diffusion method, it was observed that compounds have some significant activity against gram positive and gram-negative bacteria. It could thus

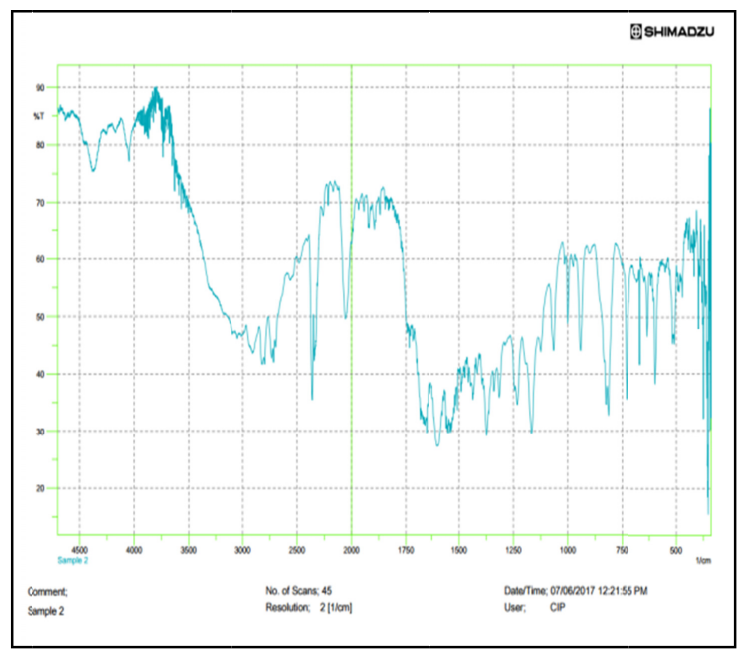

Compound II

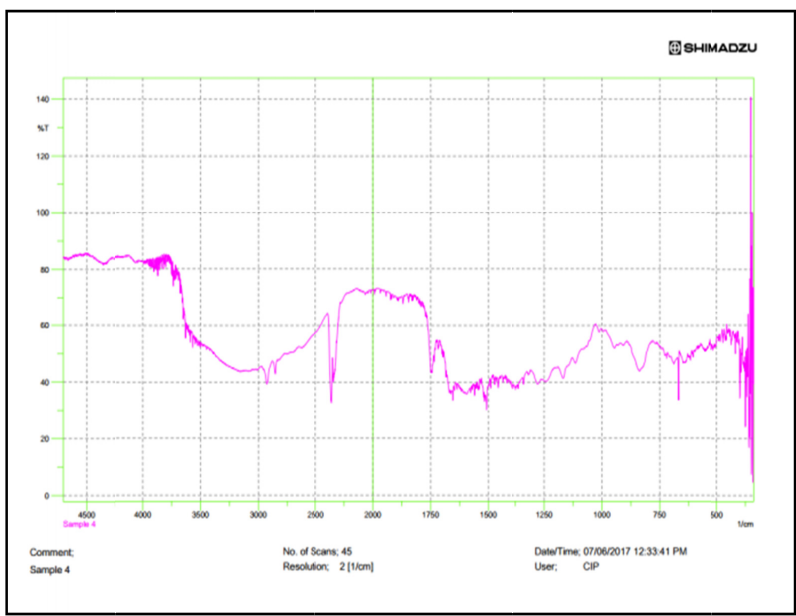

\section{Compound IV}

be assessed that antimicrobial activity of substituted 1,3,4-thiadiazole is a unique template with significant utility in medicinal chemistry. The studies revealed that the antimicrobial activity is dependent on the nature of the substituent at the thiadiazole nucleus. Also, TLC revealed that derivatives could impart significant changes in their physical and chemical properties which can be explored for further pharmacological activity including estimation of their purity, detection of impurities and assessment of in-vivo activity.

\section{CONCLUSION}

Thiadiazole ring has various biological activities. Amongst 
Sagar Sahu, et al.

Table 4. Anti-microbial activity with Gram +ve, and Gram -ve bacteria

\begin{tabular}{|c|c|c|c|c|c|c|c|}
\hline \multicolumn{8}{|c|}{ Anti-microbial activity with Gram +ve bacteria $B$. subtilis } \\
\hline Compound & $25 \mu \mathrm{g}$ & $50 \mu g$ & $100 \mu g$ & $250 \mu g$ & $500 \mu g$ & $1,000 \mu g$ & $\mathrm{MIC} \mu \mathrm{g}$ \\
\hline I & 0 & 0 & 0 & 0 & 0 & 7 & 1,000 \\
\hline II & 0 & 0 & 0 & 0 & 0 & 4 & 1,000 \\
\hline III & 0 & 0 & 0 & 0 & 5 & 3 & 1,000 \\
\hline IV & 0 & 0 & 0 & 0 & 0 & 0 & NF \\
\hline Ciprofloxacin & 8 & 10 & 15 & 19 & 22 & * & 25 \\
\hline \multicolumn{8}{|c|}{ Anti-microbial activity with Gram -ve bacteria $E$. coli } \\
\hline I & 0 & 0 & 0 & 0 & 0 & 0 & NF \\
\hline II & 0 & 0 & 0 & 0 & 0 & 3 & 1,000 \\
\hline III & 0 & 0 & 0 & 0 & 0 & 0 & NF \\
\hline IV & 0 & 0 & 0 & 0 & 0 & 0 & NF \\
\hline Ciprofloxacin & 18 & 20 & 23 & 26 & 28 & * & 25 \\
\hline
\end{tabular}

In above tables, NF indicates that MIC was not found in the concentrations screened.

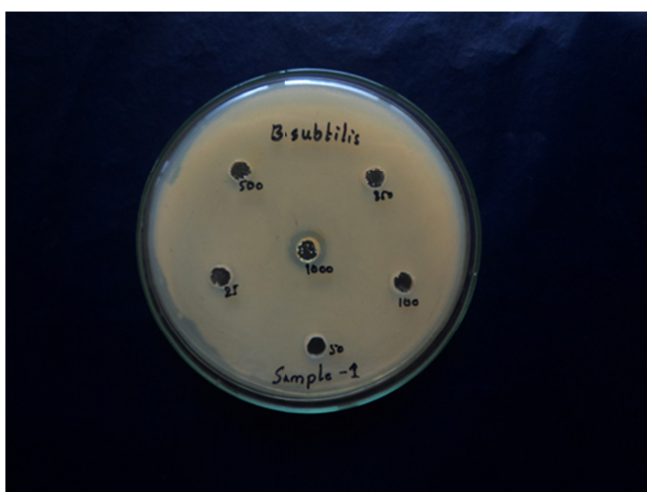

Compound I

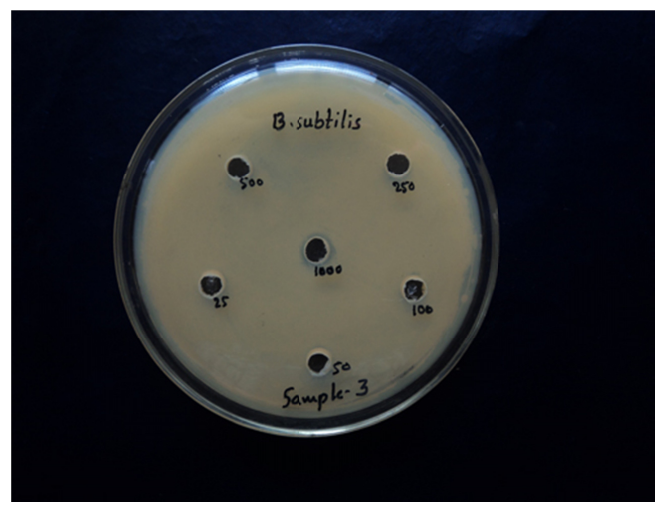

Compound III

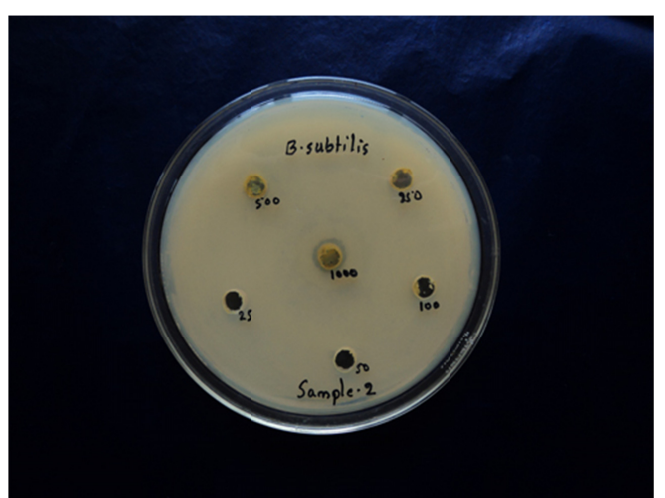

Compound II

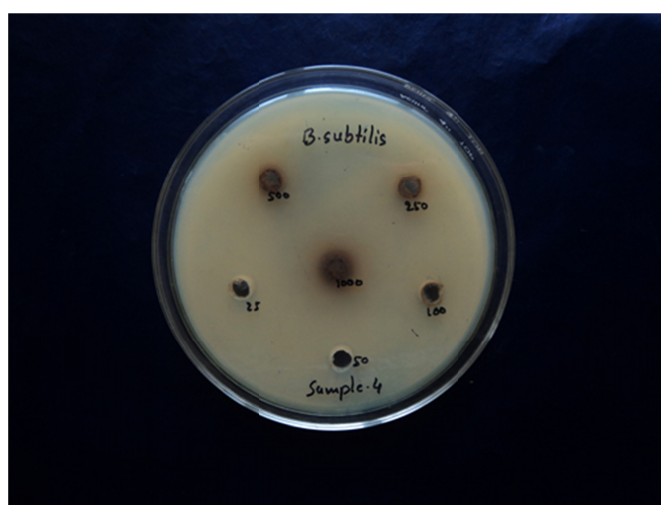

Compound IV

Figure 8. Antimicrobial Activities of compounds with Gram +ve bacteria. 


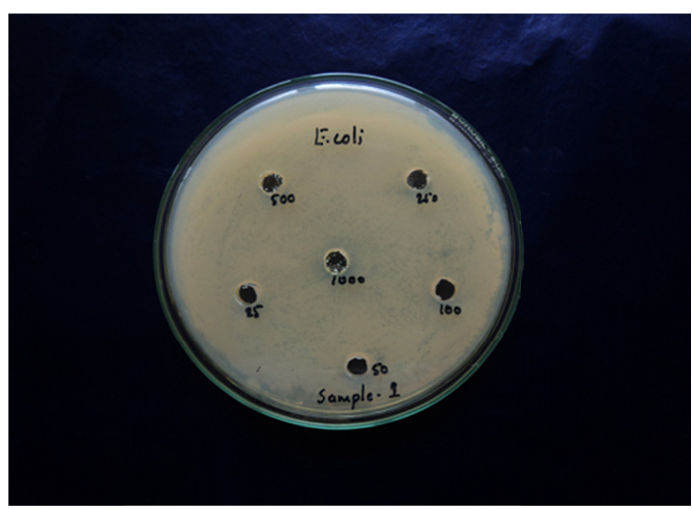

Compound I

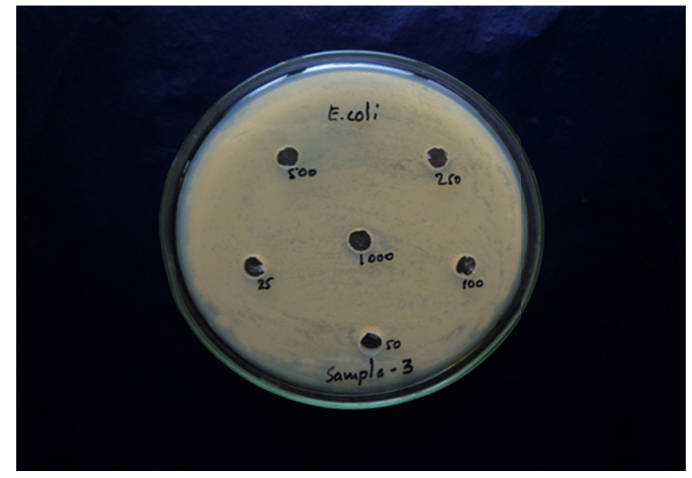

Compound III

Figure 9. Antimicrobial Activities of compounds Gram -ve bacteria.

the isomers of thiadiazole, 1,3,4-thiadiazole derivatives are widely studied due to their broad scale of pharmacological activities. Though a few pharmacological effects are exhibited by 1,3,4-thiadiazole derivatives which are currently used clinically (eg, antibacterial activity and carbonic anhydrase inhibiting activity), the substitution at Thiadiazole ring is an exigent approach to obtain agents with improved potency and lesser toxicity. Although the antibacterial activity, has been studied, other antimicrobial activities exhibited such as antifungal and antitubercular properties can also be explored.

\section{CONFLICT OF INTEREST}

The authors report no conflict of interest.

\section{ORCID}

Sagar Sahu, https://orcid.org/0000-0001-9387-0125

Tanesh Sahu, https://orcid.org/0000-0001-8914-9976

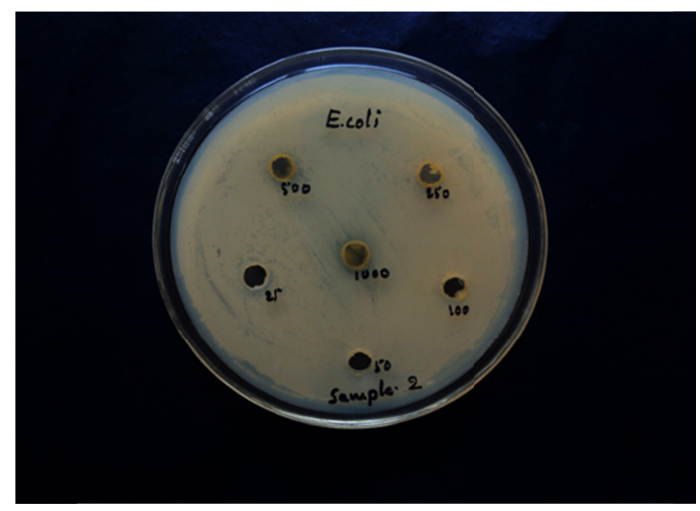

\section{Compound II}

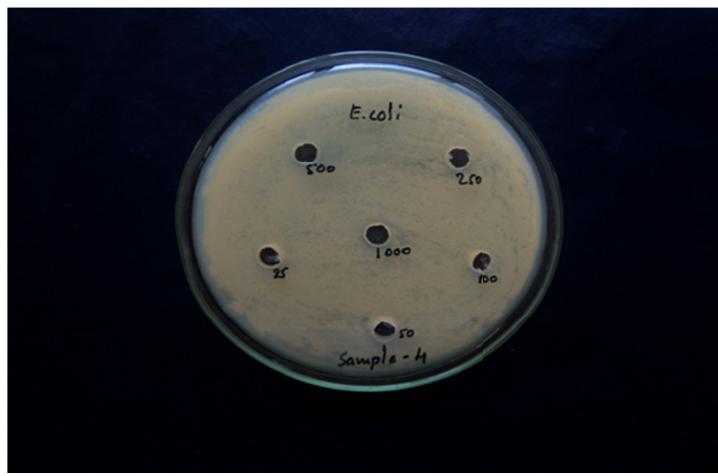

Compound IV

Gunjan Kalyani, https://orcid.org/0000-0003-1766-5095

Bina Gidwani, https://orcid.org/0000-0003-1257-723X

\section{REFERENCES}

1. Kaushal M, Kaur A. A review on some 2,5-disubstituted [1,3,4] thiadiazole substituted thiazolidinone derivatives as a potent antimicrobial agents. World J Pharm Res. 2016;5(6):1966-77.

2. Mehta D, Taya P, Neetu. A review on the various biological activities of thiadiazole. Int J Pharm Pharm Sci. 2015;7(4):39-47.

3. Rao MRK, Shil S. Some observations on thin layer chromatography technique. Int J Recent Technol Eng. 2019;8(2):1700-2.

4. Sandeep Kumar Reddy C, Azam Khan KK, Nagaraja C. A review on the determination of melting point measurement system. Int J Adv Res Electr Electron Instrum Eng. 2016;5(2):975-9.

5. Furniss BS, Vogel AI. Vogel's textbook of practical organic chemistry. 5th ed. Harlow: Pearson/Prentice Hall; 2009. p. 2368, 1204-10.

6. Serban G, Stanasel O, Serban E, Bota S. 2-Amino-1,3,4-thiadiazole as a potential scaffold for promising antimicrobial agents. 
Drug Des Devel Ther. 2018;12:1545-66.

7. Kaur P. 1,3,4-thiadiazole and its derivatives: a review on biological activities. Int J Univ Pharm Bio Sci. 2017;6(3):246-80.

8. Abo-Bakr AM, Hashem HE. New 1,3,4-thiadiazole derivatives: synthesis, characterization, and antimicrobial activity. J Heterocycl Chem. 2019;56(3):1038-47.

9. Parmar KC, Umrigar NH. Review article on synthesis of 1,3,4thiadiazole derivatives and it's biological activity. J Chem Pharm Res. 2017;9(6):202-14.

10. Adnan S, Mohammed AJ, Thamer H. Synthesis and identification of some derivatives of 1,3,4-thiadiazole. J Chem Pharm Res.
2015;7(10):1000-11.

11. Sayed A, Zaki Y, Aish E. A convenient route for the synthesis of new thiadiazoles. Turk J Chem. 2016;40(1):184-91.

12. Syed MA, Reddy YRP, Chandrasekhar KB. Design, one-pot synthesis and biological evaluation of imidazo[2,1-b] [1,3,4] thiadiazole Derivatives for their anti-tubercular and antifungal activity. J App Pharm Sci. 2018;8(7):21-7.

13. Jain AK, Sharma S, Vaidya A, Ravichandran V, Agrawal RK. 1,3,4-thiadiazole and its derivatives: a review on recent progress in biological activities. Chem Biol Drug Des. 2013;81(5):557-76. 